Marileena Koskela \& Markus Vinnari (editors)

\title{
FUTURE OF THE CONSUMER SOCIETY
}

Proceedings of the Conference "Future of the Consumer Society" 28-29 May 2009, Tampere, Finland 
FFRC eBOOK 7/ 2009

\title{
FUTURE OF THE CONSUMER SOCIETY
}

\author{
Proceedings of the Conference \\ "Future of the Consumer Society" \\ 28-29 May 2009, Tampere, Finland
}

\section{Editors}

Marileena Koskela

Markus Vinnari 
Marileena Koskela, Project Manager

Turku School of Economics, Finland Futures Research Centre

marileena.koskela@tse.fi

Markus Vinnari, Research Scientist

University of J oensuu, Faculty of Social Sciences and Regional Studies

markus.vinnari@joensuu.fi

Copyright $\odot 2009$ Writers \& Finland Futures Research Centre, Turku School of Economics

ISBN 978-951-564-968-3

ISSN $\quad 1797-132$

Layout Katariina Yli-Heikkilä, Anne Arvonen

Finland Futures Research Centre

Turku School of Economics

Rehtorinpellonkatu 3, Fl-20500 Turku

Korkeavuorenkatu 25 A 2, FI-00130 Helsinki

Pinninkatu 47, Fl-33100 Tampere

Tel. +358 24814530

Fax +35824814630

www.tse. fi/ tutu

tutu-info@tse.fi, firstname.lastname@tse.fi

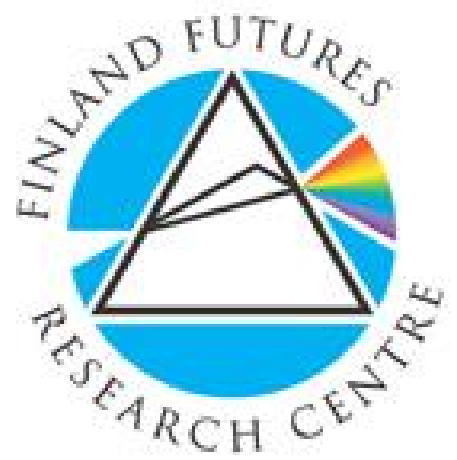




\title{
CONSUMERS' PERCEPTIONS OF SUSTAINABLY PRO- DUCED FOOD - A FOCUS GROUP STUDY
}

\author{
Kukka-Maaria Ulvila ${ }^{a}$, Ari Paloviita a and Antti Puupponen ${ }^{b}$ \\ ${ }^{\text {a }}$ School of Business and Economics, University of J yväskylä, Finland \\ ${ }^{b}$ Department of Social Sciences and Philosophy, University of J yväskylä, Finland
}

\begin{abstract}
ABST RACT - The purpose of this study is to provide information on consumers' perceptions of sustainably produced food products and the main product attributes that influence consumer's buying behaviour in the case of organic, Fair Trade and locally produced food. The paper draws on data from four focus groups. The results provide empirical insight into the motivating as well as the restricting factors which influence consumers' purchasing behaviour in the case of sustainably produced food and introduce the emerging key themes associated with the attributes of sustainably produced food products.
\end{abstract}

\section{INTRODUCTION AND BACKGROUND}

Prior research concerning consumer perceptions of sustainably produced food is somewhat limited. By sustainably produced food we mean in this paper organic food, locally produced food and food that is produced according to the principles of Fair Trade.

According to the European Commission Directorate General for Agriculture and Rural Development of the European Commission, organic food is food that is grown without most artificial fertilizers or pesticides in a way that emphasizes crop rotation, makes the most of natural fertilizers and ensures that the life of the soil is maintained. Animals are fed with organic feed and kept in ways which minimize the need for medicines and other chemical treatments. ${ }^{1}$ In Finland the recent discussion about organic food production has often related to its environmental impacts. However, organic farming is still evolving. Its development is connected to general agricultural transformation, which seems to be continuous. ${ }^{2}$

The European Fair Trade Association (EFTA) defines Fair Trade as a trading partnership which is based on dialogue, transparency and respect. This partnership seeks greater equity in international trade and contributes to sustainable development by securing the rights of and offering better trading conditions to producers and workers especially in the developing countries. ${ }^{3}$

The concept of local food is quite ambiguous. It can be shortly described as local food systems or short food chains where the food is produced near the consumer. ${ }^{4}$ In Finland local food has a specific regional economic aspect. From the Finnish public policy's viewpoint the goal is to develop profitable rural entrepreneurship by the way of local food. ${ }^{5} \mathrm{~A}$ report produced by Defra ${ }^{6}$ claims that there is a clear cause and effect relationship for food miles for environmental, social and economic burdens associated with transport. Hence, locally produced and consumed food may have a positive contribution to sustainable consumption. However, local food is a rather recent and marginal phenomenon in present Finnish agricultural context. Local food's share of the total agricultural output is as yet very small. ${ }^{7}$

Research has been done, among others, on consumer perceptions of organic food and farm animal welfare 8 , consumer motivations in purchasing organic food', consumer's willingness to pay for Fair Trade coffee ${ }^{10}$, consumer preference for organic, eco-labeled and conventional apples ${ }^{11}$ as well as on consumer perceptions of local, national and imported foods in the United Kingdom ${ }^{12}$.

However, most of these studies focus on a specific case product, such as coffee or apples, or only on one of the areas of sustainably produced food. Moreover, previous studies of product attributes or perceptions of food products have mostly focused on specific product attributes such as safety or nutritional value $^{13}$ thus leaving out all the other possible product attributes.

So far, however, there has been little discussion about consumer perceptions of all of the three sustainably produced foods; organic, Fair Trade and local food together. The purpose of this study is to pro- 
vide information on Finnish consumers' perceptions of sustainably produced food products and the main product attributes that influence consumer's buying behaviour in the case of organic, Fair Trade and locally produced food.

No specific case product was chosen, since we did not want to narrow the focus down to specific products. However, during all the focus group discussions specific products from each of the sustainably produced food types were brought up by the consumers. These products will be further presented in the Results-chapter of this paper.

The results of this research provide empirical insight into the motivating as well as the restricting factors which influence consumers' purchasing behaviour in the case of sustainably produced food and introduce the emerging key themes associated with the attributes of sustainably produced food products.

In this study we examine consumer perceptions of food produced according to the principles of Fair Trade as well as locally and organically produced food. These three groups of sustainably produced food were chosen, since sustainably issues have been associated with them, as pointed out in the aforementioned definitions of these three sustainably produced food types. In addition, all of the three groups are claimed to contribute to sustainable development with a variety of ways.

\section{Perceptions and attributes}

Perception is the process by which one selects, organizes and interprets the physical sensations in order to make sense of them. ${ }^{14}$ In this study "perception" is used as a synonym for conception which refers to the views and opinions consumers have on sustainably produced food; what it means in their opinion and what attributes are associated with it.

Consumers perceive products as sets of attributes which determine the products performance and its utility. When making the purchase decision consumers do not necessarily purchase the product itself but its characteristics or attributes. It can be assumed that consumers have rather detailed specifications of the products or services they want and need. They then try to meet these specifications with the actual product attributes. ${ }^{15}$

\section{Quality attributes and attribute consequences}

Seeing products as a set of attributes is quite useful for defining product quality. Quality can be used to refer to the set of attributes product possesses. The overall mix of attributes can then be divided into subcategories such as safety attributes, value attributes and nutrition attributes. ${ }^{16}$

Product attributes act as quality cues for the consumer. ${ }^{17}$ Consumer choice usually involves a set of alternatives, each described by attributes. The attributes can be either concrete product attributes, such as taste, smell or price, or abstract attributes, such as safety or trustworthiness. ${ }^{18}$ Often consumers have certain expectations about the product which are based on the product attributes, in other words, quality cues. When the product is used it produces a quality experience which can deviate from the expected quality causing either satisfaction or dissatisfaction with the product.19 Quality expectations and experiences contribute to the formation of product perceptions in the consumer's mind, thus, influencing consumer choice.

Product attributes or quality cues have value to the consumer because of the consequences they are perceived to bring about. These consequences are further divided into functional and psychosocial consequences. Functional consequences refer to how the product actually performs and psychosocial consequences refer to how it feels to use the product and how other people act towards us because of our consumer behaviour. Attributes do not have consequences as such, but the consequences occur when the consumer buys and uses the product. 20

When making purchase decisions consumers focus on the consequences which the purchase of a product brings about. These consequences can be seen as benefits when they are positive. Negative consequences can be referred to as risks. In general, consumers choose actions that produce benefits and minimize risks. ${ }^{21}$ 
In previous research carried out into consumer perceptions of organic food Harper and Makatouni ${ }^{8}$ and Davies, Titterington and Cochrane ${ }^{22}$ found that consumers mainly buy organic food because of health reasons. In addition, animal welfare, safety and environmental aspects also motivate them to purchase organic whereas the high price and limited availability were perceived as restricting factors. Taste was not mentioned in these studies as a motivating attribute.

In previous research on Fair Trade food consumption consumers, in general, perceive Fair Trade products as being a socially responsible choice ${ }^{23}$. However, they are also perceived to be expensive. ${ }^{24}$ In the case of consumer perceptions of locally produced food and its attributes, the importance of credence attributes, such as trust and environmental benefits, play an important role in food choice, but then again, consumers are not necessarily willing to pay the higher price of locally produced food. ${ }^{25}$

\section{MATERIAL AND METHODS}

As there are relatively few previous studies on consumer food choice in the context of sustainably produced food products, a qualitative focus group approach was used in this study. Focus groups can be considered as a compromise between the strengths of participant observation and individual interviewing 26 . Moreover, focus groups are commonly used in generating impressions of products or other objects of interests. ${ }^{27}$ In this study, our purpose was to generate impressions of sustainably produced food products and emerging product attributes affecting the consumer food choice in Finland. Synergistic effects, richness of the data and flexibility are some of the advantages associated with focus groups. ${ }^{27}$

Four focus groups were held in November 2008, with a total of 19 Finnish consumers in Jyväskylä and in Heinola. Focus group members were recruited from an eco-shop (Group 1), a local food market (Group 2), a corner shop (Group 3) and two supermarkets (Group 4). Most of the focus group members seemed to have at least moderate habit of buying organic, local and fair trade food, especially those consumers who were recruited from an eco-shop and a local food market. It is obvious that people interested in sustainably produced food are also more willing to participate in the focus groups covering these topics. In spite of small group sizes (3-4) in Jyväskylä, it was not difficult to sustain a discussion, because of highly involved participants. There were more female $(n=12)$ than male $(n=7)$ across the groups, but this was not seen as problematic, as females tend to carry out the household shopping. ${ }^{28}$ Average age of the respondents was 44 years, ranging from 18 to 78 years. Average household size was 2.3 persons and the majority of the respondents lived in an urban area. The discussion protocol was designed to explore participants' views and experiences associated with sustainably produced food products, their views on the importance of locality and origin of the food and their views on the factors that influence their buying behaviour. Participants were also asked to tell their suggestions for increasing the demand and supply of sustainably produced food.

Each group was moderated by the same interviewer to ensure consistency in interviewing style. Additional assistance was provided by a note taker and technical assistant. Each group lasted for 90 minutes, and was digitally recorded and later transcribed. The aim of the project, assurances of anonymity and confidentiality was explained to the participants. Brief introductions were made by each of the participants, moderator and assistants.

\section{Analysis}

The recorded focus group data was transcribed and the transcripts were analysed by using qualitative thematic content analysis.

First the transcripts were reduced so that all the data irrelevant to this research and its research questions was left out and expressions which were relevant to the research were coded by using different color codes. For this study the units of analysis were sentences and entities of thoughts containing several sentences.

Next the expressions coded from the data were grouped into three categories. These categories are: health and safety attributes, value attributes and credence attributes. After this the product attributes belonging to each of these categories were identified. In the health and safety category belong abstract 
attributes associated with health and safety such as cleanness, traceability and safety. The only concrete attribute in this category is healthiness (i.e. causing or not causing concrete, diagnosable health problems such as allergic symptoms).

Value attributes category contains concrete attributes such as taste, price, appearance and abstract attributes such as traditionality and nostalgia. The credence attributes category contains product attributes which are abstract and cannot be determined even after the purchase or consumption of the product. Credence attributes category contains attributes such as animal welfare, environmental benefits, social issues, trust and health (i.e. the general feeling of a food being good for you without any concrete, medical evidence). During this phase of the analysis a classification of quality attributes for food products by Hooker and Caswell ${ }^{16}$ was used to classify the expressions from the data concerning consumer perceptions of organic food, locally produced food and Fair Trade food as well as the attributes associated with these sustainably produced food types.

Next the key themes in all three aforementioned categories were identified based on the consumers' product attribute perceptions of the three different types of sustainably produced food. These key themes will be further discussed in the following chapter.

\section{RESULTS}

Although no specific case products were chosen, there were certain products which were systematically brought up by the consumers during the focus group discussions. During the discussions the Fair Trade products which were most talked about were coffee, bananas, tea and chocolate. Organic products which were the most talked about were tomatoes, cucumbers, carrots flour, meat, eggs and milk. The locally produced food products that were mentioned most often were bread, fish, vegetables and self-picked berries and mushrooms.

\section{General consumer perceptions}

In general, consumer perceptions of organic food and locally produced food were positive whereas the perceptions of Fair Trade products were rather negative. Fair Trade was seen as a "brand which is created by grocery store chains just to get money from the consumers". It was also perceived to be unreliable and "not as fair as it's said to be". These perceptions prove rather explicitly that the Fair Trade criteria and the whole concept remain somewhat vague and unclear to consumers.

In addition to the positive perceptions of locally produced food and organic food, there were some questions raised about the definition of locally produced food and locally produced food was perceived to be a synonym for Finnish food. In this sense the concept of local food is problematic, since some food companies are trading both nationally and locally in Finland. It is, therefore, sometimes difficult to make a difference between local and non-local food in the case of same products. ${ }^{5}$

Moreover, the perceived added value of organic food was called into question when some of the consumers stated that the conventional products are enough and there is no need to buy organic.

\section{Key themes}

Based on the theme analysis of the product attributes of the three sustainably produced food types in the three attribute categories, nine key themes emerged. Themes found in the health and safety attribute category were: cleanness, traceability and physical effects. The themes which were based on value attributes category were: sacrifices, quality and traditions. In the third, credence attribute category, the themes which emerged were: good conscience, trust and intangible wellbeing.

Cleanness theme (health and safety category) was based on concrete product attributes such as purity. Consumers perceived that sustainably produced food types do not contain pesticide residues, food additives or other potentially harmful chemical residues. One of the focus group participants felt that cleanness is the reason for good taste and said: "I have noticed that organic carrots taste better. It might 
be that the there is the taste of chemical fertilizers in the conventional carrots and not in the organic ones."

The second theme was traceability (health and safety) and it is based on safety and the knowledge of food origin. The theme was associated with both organic and locally produced food in such a way that both food types were perceived as being safe whereas knowledge of food origin was only associated with locally produced food.

The third theme is named physical effects (health and safety), since it is based on the concrete health attribute that is the diagnosed health impacts such as the absence of physical, lactose intolerance symptoms when drinking organically produced milk instead of conventionally produced milk. The theme, in the case where conventional foods cause allergic symptoms, was connected to organic food and locally produced food.

Sacrifices theme (value attributes category) was based on price and time, since consumers perceived sustainably produced food products as expensive and their purchasing as time consuming. This theme can be associated with all the sustainably produced food types

The fifth theme is quality (value attributes) and it was based on concrete product attributes, that is, taste, freshness, appearance and quality defects. The theme can be associated with all the sustainably produced food types. Positive quality attributes, such as good taste and freshness were associated with organic and locally produced food whereas bad taste, unpleasant appearance and quality defects were associated with Fair Trade food products.

The sixth theme is traditions (value attributes) and it is based on the abstract product attributes such as nostalgia, simplicity and customs. Organic food products and locally produced food were perceived to contain attributes such as traditionality, simplicity and nostalgia (i.e. some of the food attributes, such as good taste, bring back memories from one's childhood). One of the focus group participants stated that: "Almost everyone has childhood memories of what a tomato, a cucumber, peas or potatoes tasted like. When you manage to find that same taste from somewhere, you just have to go and get it."

Good conscience (credence attributes category) theme was based on animal welfare, social issues and environmental issues attributes. The theme was connected with all three types of sustainably produced food. Organic food was perceived to promote animal welfare and environmental benefits (i.e. less fertilizers, pesticides and preservatives used than in conventional products). Locally produced food was associated only with positive attributes such as environmental benefits (i.e. shorter transportations than with conventional or imported food), whereas Fair Trade products were associated with social issues (i.e. helping the ones in need) and they were often also purchased to ease ones guilty conscience.

Environmental and animal welfare issues are placed in the credence attribute category, since, despite the plethora of environmental labels and information campaigns which aim to educate the consumers, the content of green claims and eco labels continues to remain unclear and vague to the consumers. In addition, the environmental impacts of products as well as animal welfare issues are not clearly visible to the consumers during the purchase event and, therefore, remain abstract and a matter of trusting the information given by the food producer or manufacturer.29, 30

The eighth theme is trust (credence), which can be seen also as a product attribute. Fair Trade food products were seen as questionable, since it was doubted is the idea of Fair Trade really as fair as it is said to be and to whom it is fair. One of the focus group participants commented on Fair Trade:

I have been boycotting Fair Trade products because I feel that they really are not as fair as they are said to be. [...] A big grocery store has managed to create a good brand of Fair Trade. [...] I would like to know how it is fair and to whom.

In terms of organic products, trust contained both positive and negative attributes. Consumers feel that it is difficult to be sure if can one trust that organic products truly differ from or are healthier than the conventional products. Locally produced food was perceived to be a healthy choice.

The ninth theme was named intangible wellbeing (credence) and it is based on health attributes which cannot be medically diagnosed, but are solely based on consumer's impressions of something being "good for oneself". The theme was associated with locally produced and organic food. 


\section{DISCUSSION AND CONCLUSIONS}

The purpose of this study was to provide information on Finnish consumers' perceptions of sustainably produced food products and the main product attributes that influence consumer's buying behaviour in the case of organic, Fair Trade and locally produced food. This was done by introducing the emerging key themes associated with the attributes of sustainably produced food products.

This study produced results which, to some extent, corroborate the findings of the previous work in this field. In contrast to earlier findings, however, the themes under health and safety attribute category, were not the most important themes to the consumers when considering all the three sustainably produced food types. In addition, a rather unanticipated finding was that consumer perceptions of organic food, locally produced food and Fair Trade food products differ substantially from each other.

The results of this study indicate that cleanness and quality are the themes which motivate consumers to purchase organic, Fair Trade or locally produced food whereas the sacrifices theme is seen as a restricting factor. However, the significance of good conscience, trust, traceability, traditions and physical effects is undeniable when determining the motivating and restricting factors which influence consumers' purchasing behaviour.

On the one hand, Finnish consumers do not purchase organic, Fair Trade or locally produced food only because of their concrete attributes, but great emphasis is put on the abstract attributes such as animal welfare, environmental issues, trust and nostalgia.

On the other hand, concrete attributes such as taste and price have a very important role in consumers' minds when making the decision weather to purchase sustainably produced or conventional food. In fact, overall product quality, including taste, freshness and appearance, seems to be the most significant motivating factor for consumers to buy organic or locally produced food, since these food products are perceived to be superior in taste when compared with conventionally produced food.

The most significant restricting factor to purchasing seems to be the price of the products in all three types of sustainably produced food. However, the results of this study indicate that consumers are willing to pay the price premium of sustainably produced food, since delicious taste is an attribute which brings such benefits to the consumer that tasty products, such as organic tomatoes, are perceived to be worth their higher price.

In terms of the consequences that the product attributes are perceived to bring about to the consumer, the positive attributes can be seen as benefits and the negative attributes as risks.

Regarding organic food there are perceived benefits in all three attribute categories under the following themes: cleanness, traceability, physical effects, quality, traditions, good conscience, trust and intangible wellbeing. The only risks are connected to the sacrifices theme due to the high price of organic products as well to the intangible wellbeing theme.

The same benefits apply to locally produced food and the only perceived risk is connected with the high price of the products. However, according to previous studies a further challenge for local food in Finland is also the complexity of the local network. From the optimistic view point, the farmers solve most of these network problems by their own activity. On the other hand, public policy could be helpful on condition that farmers are left with reasonable space for self-governance. ${ }^{7}$

In case of Fair Trade products the risks are more numerous than the benefits, since Fair Trade products, since rather negative themes are mentioned in association with all three attribute categories. The risks linked to Fair Trade products were financial sacrifices, mistrust, inferior quality in the form of bad taste and unpleasant appearance. However, their benefits are perceived to be cleanness and the possibility to help the ones in need that is the good conscience theme.

\section{Marketing implications}

The findings of this study suggest that although consumers seem to have positive perceptions and appreciations particularly of organic and locally produced food, purchasing these products is perceived to be troublesome and requiring a great deal of time. Consumers feel that they do not have the time to go 
through the trouble of finding information about sustainably produced food or to go to many stores in search of certain products.

Consumers are, therefore, inclined to purchase the same, conventional products that they are used to purchasing, since this makes grocery shopping easy and convenient. Based on the theme analysis it is possible to conclude that in addition to the differences in consumer perceptions, there are also differences in the quality attributes which consumers associated with organic, locally produced and Fair Trade food products. Positive attributes were mainly associated with organic and locally produced food whereas Fair Trade products were associated with more negative attributes.

Furthermore, consumers do not perceive sustainably produced food as an unambiguous concept and there are significant differences in perceptions as well as product attributes. For example the results of this study suggest that consumers do not have enough information about Fair Trade food products and do not trust them as much as they trust organic or locally produced food.

The findings of this study suggest that when planning the marketing of sustainably produced food, marketers should possibly take into account the fact that consumers' perceptions of and the product attributes associated with the different types of sustainably produced food may differ significantly. Moreover, the findings of this study also suggest that when planning the promotion of sustainably produced food emphasis should indeed be put on promoting the abstract attributes of the products, but the most important concrete attribute, taste, should not be left out. These findings are significant especially for the Finnish food trade system and its competitiveness, because it has been estimated that in the future the retail chains are growing stronger due to internationalization and centralization. ${ }^{31}$

\section{Further research}

This study has its limitations. The results must be considered as an outcome of the Finnish cultural and socioeconomic context. Thus, comparative focus groups in different contexts dealing with sustainably produced food could be conducted. In addition, this study only focuses on product attributes and perceptions, while further research could be undertaken to explore consumers' attitudes towards sustainably produced food. Moreover, future research could broaden the perspective from consumer attitudes towards the attitudes of food marketers, manufacturers and producers. This would enable to study the means to create sustainably produced food networks.

\section{REFERENCES}

1 Directorate General for Agriculture and Rural Development of the European Commission. (2009) Organic farming - good for nature, good for you. Available http:// ec.europa.eu/agriculture/ organic/ home en. Cited $24^{\text {th }}$ April 2009.

Seppänen, L. (2004) Learning Challenges in Organic Vegetable Farming. An Activity Theoretical Study of On-Farm Practices. University of Helsinki, Institute for Rural Research and Training. Publications 1. 74 p. European Fair Trade Association (2006) EFTA: J oining Fair Trade Forces. Available http:// www.europeanfair-trade-association.org/ efta/ Doc/What.pdf. Cited 24th April 2009. Urban-Rural Interaction (2001) Report of the Working Group of Urban-Rural Interaction. Helsinki, Ministry of the Interior. $34 \mathrm{p}$.

Sireni, M. (2007) Vaihtoehtoista ruoantuotantoa kehittämässä. Analyysi maakunnallisista elintarvikestrategioista (Developing alternative food production. An analysis of regional food strategies). University of J oensuu, Reports of The Karelian Institute, N:o 6/2007. 60 p. (In Finnish) DEFRA (2005) The Validity of Food Miles as an Indicator of Sustainable Development. London, DEFRA. $103 \mathrm{p}$.

Järvelä, M., J okinen, P., Huttunen, S. \& Puupponen, A. (2009) Local Food and Renewable Energy as Emerging New Alternatives of Rural Sustainability in Finland. European Countryside Vol. 1, No. 2, pp. 113124.

8 Harper, G. C. \& Makatouni, A. (2002) Consumer Perceptions of organic food and farm animal welfare. British Food J ournal Vol. 104, No. 3/4/5, pp. 287- 299.

9 Zanoli, R. \& Naspetti, S. (2002) Consumer Motivations in the Purchase of Organic Food - A Means-End Approach. British Food J ournal Vol. 104, No. 8, pp. 643- 653.

10 De Pelsmacker, P., Driesen, L. \& Rayp, G. (2005) Do Consumers Care about Ethics? Willigness to pay for Fair-Trade Coffee. J ournal of Consumer Affairs Vol. 39, No. 2, pp. 363- 385. 
Loureiro, M. L., McCluskey, J \& Mittelhammer, R. (2001) Assessing Consumer Preference for Organic, Eco-labeled and Regular Apples. J ournal of Agriculture and Resource Economics Vol. 26, No. 2, pp. 404416.

Chambers, S., Lobb, A., Butler, L., Harvey, K. \&Traill, B. (2007) Local, National and Imported Foods: a Qualitative Study. Appetite Vol. 49, pp. 208-213.

Caswell, J .A. (1998) Valuing the Benefits and Costs of Improved Food Safety and Nutrition. The Australian J ournal of Agriculture and Resource Economics Vol. 42, No. 4, pp. 409-424.

Solomon, M., Bamossy, G. \&Askegaard, S. (2002) Consumer Behaviour: A European Perspective (2nd edition). Upper Saddle River, NJ : Prentice Hall. 630 p.

Lancaster, K. J . (1966) A New Approach to Consumer Theory. The J ournal of Political Economy Vol. 74, No. 2, pp. 132- 157.

Hooker, N. H. \& Caswell, J . A. (1996) Regulatory Targets and Regimes for Food Safety: A Comparison of North American and European Approaches. In Caswell, J .A (ed.) The Economics of Reducing Health Risks from Food. Storrs CT: Food Marketing Policy Center. pp. 1- 17.

Steenkamp, J .-B. E. M. (1990) Conceptual Model of the Quality Perception Process. Cited in Grunert, K. G. (2002). Current Issues in Understanding Consumer Food Choice. Trends in Food Science \& Technology Vol. 13, pp. 275- 285.

Bettman, J. R., Luce, M. F. \& Payne, J. W. (1998) Constructive Consumer Choice Process. J ournal of Consumer Research Vol. 25, pp. 187- 217.

Grunert, K. G. (2002) Current Issues in the Understanding of Consumer Food Choice. Trends in Food Science \& Technology Vol. 13, pp. 275- 285.

Olson, J . C. \& Reynolds, T. J. (2001) The Means-End Approach to Understanding Consumer Decision Making. In Reynolds, T. J . \& Olson, J . C. (eds.) Understanding Consumer Decision Making: The Means-End Approach to Marketing and Advertising Strategy. Mahwah, NJ , Lawrence Erlbaum Associates. $447 \mathrm{p}$. Gutman, J. (1982) A Means-End Chain Model Based on Consumer Categorization Processes. J ournal of Marketing Vol. 46, pp. 60-72.

Davies, A., Titterington, A. J \& Cochrane, C. (1995) Who Buys Organic Food? A Profile of the Purchasers of Organic Food in Northern Ireland. British Food J ournal Vol. 97, No. 10, pp. 17- 23.

McCluskey, J . J . \& Loureiro, M. L. (2003) Consumer Preferences and Willigness to Pay for Labeling: a Discussion of Empirical Studies. J ournal of Food Distribution Research Vol. 34, No. 3, pp. $96-102$.

Loureiro, M. L. \&Lotade, J . (2005) Do Fair Trade ans Eco-labels in Coffee Wake Up the Consumer Conscience? Ecological Economics Vol. 53, pp. 129- 138.

Weatherell, C., Tregear, A. \&Allinson, J. (2003) In Search of the Concerned Consumer: UK Public Perceptions of Food, Farming and Buying Local.J ournal of Rural Studies Vol. 19, pp. 233-244.

Morgan, D.L. (1997). Focus groups as qualitative research. Thousand Oaks: Sage. 85 p.

Stewart, D.W. \& Shamdasani, P.N. (1990) Focus groups: Theory and practice. Newbury Park: Sage Marshall, D.W. \&Anderson, A.S. (2000) Who's responsible for food shopping? A study of young Scottish couples in their "honeymoon" period. International Review of Retail, Distribution and Consumer Research Vol. 10, No. 1, pp. 59- 72.

Niva, M., Heiskanen, E. \&Timonen, P. (1996) Environmental information in consumer decision making. National consumer research centre, Offprints 7. Helsinki. $16 \mathrm{p}$.

Pedersen, E. R. \& Neergaard, P. (2006) Caveat Emptor - Let the Buyer Beware! Environmental Labelling and the Limitations of 'Green' Consumerism. Business Strategy and the Environment Vol. 15, pp. 15- 29. Niemi, J. \& Ahlstedt, J . (eds.) (2008) Suomen maatalous ja maaseutuelinkeinot 2008 (Finnish agriculture and agricultural industry 2008). Agrifood Research Finland, Economic Research, Publications 108. (In Finnish) 